Editorial

\title{
Critical Theory and Being Critical: Connections and Contradictions
}

\author{
Robert E. Gutsche, Jr. \\ Department of Sociology, Lancaster University, Bailrigg, LA1 4YW, UK; E-Mail: r.gutschejr@lancaster.ac.uk
}

Submitted: 12 March 2021 | Published: 6 April 2021

\begin{abstract}
This editorial responds to a professionalization and constrained notion of "critical theory" to argue for an academic and humanist-centered approach to developing debates and discussions around the future of critical theory and "being critical."

\section{Keywords}

critical theory; digital media; journalism

\section{Issue}

This editorial is part of the issue "Critical Theory in a Digital Media Age: Ways Forward" edited by Robert E. Gutsche, Jr. (Lancaster University, UK).
\end{abstract}

(C) 2021 by the author; licensee Cogitatio (Lisbon, Portugal). This editorial is licensed under a Creative Commons Attribution 4.0 International License (CC BY).

\section{Introduction}

Increasing digitization of journalism and other forms of media continue to attract the attention of social scientists and sociological approaches to interpret change and to predict the future for audiences and producers alike. However, emerging forms of surveillance and sousveillance among and by media producers, threatened privacy amid massive data collection, and globalization at the center of digital communication across continents and economies warrants a revision of critical theory within media and communication studies. While critical theory provides promise for much engagement with new technologies and interactions of power systems in media and communication, the area largely remains spoken about in select corridors of scholarship and certainly outside of industry discussions about media and communication.

There is a need to revisit (and return to) the works that emerged in the 1970s and 1980s in the U.K. and U.S., not only as a targeted approach against increasing neoliberalism globally, but as commentary about the dangers of established social, scientific and sociological approaches to politics, advertising, and journalism that failed to question dominant ideologies of the day. The work of scholars most aligned with contemporary attempts at critical scholarship in journalism and media research amid technological change include Stuart Hall,
Hanno Hardt, bell hooks, Marx, and, of course, a host of postmodern theorists. While studies with a focus on technological determinism keep pace with the technological advancements of media, captured there is a threat to the role, forms, and functions of critical theory in journalism, media, and communication scholarship. In turn, we are missing deeper meanings that exist within dominant, normative assessments of journalism and the Fourth Estate, sociological inquiries into journalistic boundary work, and deterministic interpretations of technology that remain at the forefront of popular journalism and media studies.

I am not arguing against the need for normative work that asks difficult questions about technological advancement or positions journalism fully outside of fulfilling its democratic aims; however, my wish is for critical theory to engage and enlighten researchers to ask about and apply critical positions in order to develop those theories, unveil new ideas about current questions, and plow a way forward for critical perspectives in increasingly digital means of communication.

When I started this thematic issue, I sent out this call to leading scholars, asking if they would be willing to participate. Time pressures and competing projects kept some people out of submitting. Others felt they couldn't write about "critical theory" in a journal that charges authors for open access publication rights. Even one well-published and recognized scholar of critical 
theory took issue with the journal's open access rate and rebuked my offer to consider publishing an essay on the topic. In their message to me, they sent comments to the effect that publishing such a thematic issue-and having to pay for it-was a reflection of my own limited intellect and commitment to critical approaches. The scholar, who I am not naming, wrote:

Unfortunately, you do not seem to understand the basics of Critical Theory. Everyone who has read a bit of Adorno will be wary of capitalist online publishing as it is just a new form of the culture industry-you are not...

This is not just sad, but disgusting...

I wish you worst of luck with this special issue and am sure it will be a complete failure...

Learn to understand some foundations of the critical political economy of online publishing...

It is sad that many scholars will recognize that tone and contempt. As an Associate Editor of another journal, I, too, sometimes (thankfully, not often) see such language and personal attacks even from people and in situations where scholars think they are fighting for the sanctity of scholarship itself. But is this kind of close-minded approach to "critical theory" today what we really want from scholarship of tomorrow? Is this critical theory, or are we "being critical"? Are they one and the same? Is there room in "critical theory" for a more, open way of thinking about intellectual pursuits and an idea of "being critical" that doesn't fit the establishment's expectations?

There is no doubt that I put into the call the names of "critical theory" scholars that we most identify with in related discussions. And maybe I should have called then for a wider range of names and perspectives. I am glad the articles that appear in this issue have done so, seeing this as an opportunity to write in the name of critical theory and in producing theoretical cases and discussions that show the world of critical theory can emerge beyond the often confining and hegemonic positions of accepted theory. (And just as a note, publication costs for articles in this issue that qualified were waived.)

My rationale for publishing in this journal, one that does have a (high) fee for its open access rights, was in response to its first years of celebrating technological traditions, sometimes without "critical theory" to the point that we seemed to be reading and writing "to each other." At a time when Western governments are increasingly attacking "critical" thought taught in places of education, it may be that just as we need to revisit where we believe "critical theory" fits in our scholarship, we need to think about being critical in ways that support one another, unite against oppression, and do so in ways that elevate kindness (where appropriate) over being right. Just as we might debate the definitions of "critical theory" and discuss if that's the same as "being critical" or informing such an act, we should debate the future of how such approaches are being produced in graduate programs, particularly $\mathrm{PhD}$ programs in fields of Communication, where industry, metrics, and quantitative methods seem to have (again) strengthened their roots in the past decade, particularly in the U.S.

The same debate about the role of "critical theory" and "being critical" should be had in tenure and promotion policies across the globe, our obsession with article citations, the movement of university "engagement" about bringing in money than actually talking to someone off-campus about their interests, needs, and contributions. "Being critical," then, isn't to dismiss "critical theory," but is a light step in examining just how wellsteeped some are in the conventions of elite thought, and perhaps we could use some time to consider the intersections of these ideas, and their diversions, fit in how we encourage and support others in their own efforts to bring about ideas of the world that challenge the status-quo. The job of scholarship is hard enough. Writing and working against systems (and each other?) takes a special spirit, and we should remember that first and foremost in academic debates about what "critical" is and what it can be.

\section{Acknowledgments}

Thanks to the editorial staff, peer reviewers and contributors for their work in putting this issue together, and to Oscar Westlund for the encouragement to do it.

\section{Conflict of Interests}

The author declares no conflict of interests.

\section{About the Author}

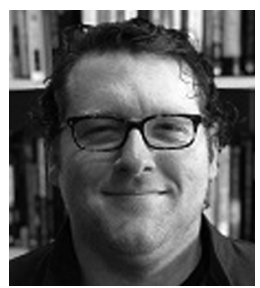

Robert E. Gutsche, Jr. is Associate Professor (Senior Lecturer) in Critical Digital Media Practice in the Department of Sociology at Lancaster University in Lancaster, UK. A former journalist, his scholarship examines issues of power in newswork and content. He is currently Associate Editor of Journalism Practice and the author or editor of several books on journalism and its connections to geography, race, climate change discourse, and news rhetoric surrounding Donald Trump. 